\title{
LA LEY Y EL CÓDIGO EN LAS CONSTITUCIONES PROVINCIALES INDEPENDENTISTAS DE LA NUEVA GRANADA: ¿PARA QUÉ MÁS?
}

\section{Andrés Botero Bernal}

Fecha de recibido: 29 de julio de 2013

Fecha de aprobado: 27 de septiembre de 2013

Artículo resultado de investigación

Forma de citación: Botero, A. (2013). La ley y el código en las constituciones provinciales independentistas de la Nueva Granada. Revista Prolegómenos. Derechos y Valores, 16, 32, 203-220.

\section{Resumen}

El presente trabajo es resultado del proyecto de investigación "La cultura jurídica en la Antioquia del siglo XIX", financiado por la Universidad de Medellín (Colombia), así como del proceso de formación doctoral en la Universidad de Huelva, bajo la dirección del profesor Dr. Carlos Petit Calvo. Igualmente, este texto es un resumen y adaptación de un capítulo de una obra mayor que está próxima a ser editada en la Universidad de Medellín. El interés del presente escrito no es otro que el de identificar el deseo estatalista que, sin renunciar del todo al sistema colonial, se encuentra en el primer constitucionalismo neogranadino, a partir del maridaje complejo entre distintas posturas teóricas presentes en la mente de los criollos independentistas. Para ello, este trabajo analiza el concepto de ley y de código como los máximos anhelos de las constituciones independentistas hispanoamericanas. Este ideal explica el título del presente texto. Nos fundamos en ejemplos tomados de la Constitución antioqueña de 1812 que bien pueden extenderse en sus planteamientos generales a las demás constituciones provinciales de la Nueva Granada, en tanto es más lo que las une que lo que las separa.

\section{Palabras clave}

Nueva Granada, constitución independentista, independencia de Hispanoamérica, Antioquia

\footnotetext{
Abogado, licenciado en filosofía y letras, especialista en docencia universitaria, especialista en contextualización psico social del crimen, diplomado en conformación y gestión de grupos de investigación, diplomado en actualidad universitaria y diplomado en formación en ambientes virtuales. Máster Europeo Universitario in storia e comparazione delle istituzioni politiche e giuridiche dei Paesi dell'Europa Mediterranea en las universidades de Messina (Italia), Milano (Italia), Autónoma de Madrid (España) y Córdoba (España). Diploma de Estudios Avanzados en la Universidad de Huelva (España). Doctor en Derecho de la Universidad de Buenos Aires (Argentina).

Profesor e investigador tiempo completo de la Facultad de Derecho de la Universidad de Medellín; profesor invitado en universidades y centros de investigación de Estados Unidos, Argentina, México, Cuba, Chile, Brasil, España, Italia, Austria y Alemania. Los campos de investigación y estudio giran en torno a la historia del derecho y la iusfilosofía.
} 


\title{
THE LAWS AND CODES ON THE NEW GRANADA INDEPENDENCE CONSTITUTIONS: WHY MORE?
}

\begin{abstract}
This work is a result of the research project "The legal culture in XIX century Antioquia", funded by the Universidad de Medellin (Colombia), and of the doctoral training process at the Universidad de Huelva (Spain), under the direction of professor Dr. Carlos Petit Calvo. In addition, this text is an abstract and an adaptation from a chapter of a larger work which is about to be published in the Universidad de Medellin. The interest of this article is none other than to identify the statist desire that, without completely renouncing to the colonial system, is within the first constitutionalism of the New Granada, starting from the complex mix between different theoretical positions present on the minds of the pro-independence Creoles. To do so, this paper analyzes the concept of law and code as the highest aspirations of the Spanish American independence constitutions. This ideal explains the title of this text. It took as foundation the examples found in the 1812 constitution of Antioquia which may well extend their general approaches to other provincial constitutions of the New Granada, as it is more that unites them than divides them.
\end{abstract}

\section{Keywords}

New Granada, independence constitution, independence of Spanish America, Antioquia

\section{AS LEIS E OS CÓDIGOS NA NOVA GRANADA CONSTITUIÇÕES INDEPENDÊNCIA: POR QUE MAIS?}

\begin{abstract}
Resumo
Este trabalho é resultado do projeto de pesquisa "A cultura jurídica no século XIX Antioquia", financiado pela Universidade de Medellín (Colômbia), e processo de formação de doutorado na Universidade de Huelva (Espanha), sob a direção do Professor Dr. Petit Carlos Calvo. Além disso, este texto é um resumo e uma adaptação de um capítulo de um trabalho maior acerca que deve ser publicado na Universidade de Medellín. O interesse deste artigo não é outro senão a identificação de identidade que o desejo estatista, completamente sem renunciar ao sistema colonial, está dentro do primeiro constitucionalismo da Nova Granada, a partir da mistura complexa entre diferentes posições teóricas presentes nas mentes dos pro-independência crioulos. Para isso, este artigo analisa o conceito de lei e código como as mais altas aspirações das espanholas constituições independência americanos. Este perfeito Explica o título deste texto. Demorou fundação como os exemplos encontrados na Constituição de 1812 de Antioquia que pode muito bem estender a outras abordagens suas constituições provinciais gerais da Nova Granada, como é mais isso que os une do que dividi-los.
\end{abstract}

\section{Palavras-chave}

Nova Granada, Constituição da independência, Independência da América espanhola, Antioquia. 


\section{INTRODUCCIÓN}

Primero, se anota que en este texto se hace uso de las siguientes siglas: AHM (Archivo Histórico de Medellín, Colombia); AHJM (Archivo Histórico Judicial de Medellín, Colombia); AHA (Archivo Histórico de Antioquia, Colombia); AGN (Archivo General de la Nación, Colombia) y AGI (Archivo General de Indias, Sevilla, España).

Dentro del constitucionalismo provincial y, especialmente, en la constitución antioqueña de 1812 (que nos sirvió de base para este estudio), encontramos uno de los puntos germinales del proceso legalista - estatalista de la Nueva Granada en lo corrido del siglo XIX, que más adelante dará lugar al híbrido formalista que padece hoy día este país.

Este proceso, que se presenta en alguna medida en el constitucionalismo provincial neogranadino, quedó patente con la adhesión ideológica al modelo constitucional europeo (especialmente en lo atinente a la Constitución de 1791 y a las declaraciones de derechos, así como en el ideal de elaboración de códigos presente en la mayoría de cartas constitucionales de la época) ${ }^{1}$ y con la evolución de procesos prácticos de ejercicio del poder que, si bien parten de cuerpos criollos colegiados, van poco a poco adentrándose en formas de gobierno unipersonales y centralistas, como fue el caso de Colombia en la segunda república² .

1 Como por ejemplo el Estatuto de Bayona (1808): "Las Españas y las Indias se gobernarán por un solo código de leyes civiles y criminales" (art. xcvi), "Habrá un sólo código de comercio para España e Indias" (art. cxiii). Igualmente la Constitución de Cádiz (1812): "El código civil y criminal, y el de comercio serán unos mismos para toda la Monarquía, sin perjuicio de las variaciones que por particulares circunstancias podrán hacer las Cortes" (art. 258) (Petit, 1995; Busaall, 2008, par. 44).

2 Al inicio del segundo constitucionalismo no dejaron de presentarse altercados entre los cuerpos colegiados con los unipersonales. Por ejemplo, el cabildo de Antioquia solicitó en 1824 al Congreso la modificación de una
No obstante, las constituciones provinciales intentaron una armonización de valores federales, en clara alusión al constitucionalismo estadounidense (aunque este no fue la única fuente de los federalistas), junto a una cosmovisión revolucionaria (especial pero no únicamente la francesa) e ilustrada, lo cual se creyó haber logrado al instaurar inicialmente el centro de la nación - patria no en la Nueva Granada sino en las provincias neogranadinas. De esta forma, el centralismo-nacionalismo que se leyó del constitucionalismo europeo (junto a sus declaraciones de derechos, los conceptos de soberanía popular, etc.), recayó en la provincia, y frente a Santa Fe de Bogotá se predicaba un discurso que recuerda en buena medida el sistema revolucionario norteamericano así como otros sistemas provinciales conocidos en la época ${ }^{3}$.

ordenanza municipal establecida en época de la ocupación española que señalaba la obligatoriedad de los alcaldes y los regidores (es decir, del cabildo) de buscar al gobernador para acompañarlo en días festivos a la Iglesia "de ida y vuelta". Considera el cabildo que esta disposición atenta contra los valores republicanos en tanto es una demostración de servilismo y, además, como humillante para "la corporación cívica salir de su sala en formación a la casa del gobernador para sacarlo" (A.G.N., Legajo 24, Rollo 23, Folios 603-606). La Comisión de Policía del Congreso conceptúa a favor del cabildo de Antioquia con los siguientes términos: "En ningún cantón de la República se exija de los cuerpos municipales una demostración tan servil que degrada la representación" (folio, 603). En el fondo, se trata de un intento de reafirmar la autoridad de los cuerpos representativos sobre los gobiernos unipersonales que toman fuerza inusitada.

3 Al respecto existe un interesante debate entre los que consideran que el modelo político de las "Provincias Unidas" devino de los Países Bajos (y, por qué no, del modelo cantonal suizo), los que creen que fue una recepción del modelo estadounidense y los que sugieren que se trató de un desarrollo del fuerismo español (Fraga, 1977, p. 11). Si hacemos caso a uno de los artífices del proceso hiperconstitucional neogranadino, Restrepo (1942, pp. 164-177), la idea la tomaron de Estados Unidos; sin embargo, no era desconocido para los criollos independentistas el modelo de organización política de los Países Bajos, de Suiza e incluso de la Confederación del Rin organizada por Napoleón (Levaggi, 2007, pp. 18-22 y 63-66). Precisamente en estas últimas páginas se describe la postura de Alberdi quien consideró que el término de "Provincias Unidas" pro- 
La nación católica criolla se construye hacia adentro, hacia la provincia, con cierto acento francés (aunque no únicamente francés) en lo atinente al discurso, lo cual se explica, además, en el hecho de haberse adaptado mejor a la interpretación criolla, puesto que la revolución de Estados Unidos es contra una visión estatalista de los derechos, en clave historicista-colonial ${ }^{4}$, con una profunda desconfianza de la autonomía de lo político respecto de lo social, que era todo lo contrario al proyecto político de las juntas de gobierno americanas ${ }^{5}$.

Siguiendo el análisis de esta vinculación ideológica, tenemos como prueba la consideración de la norma general como concreción de la justicia, ya que respeta el principio de igualdad

vino de Holanda, aunque también Levaggi plantea la posibilidad que fuera fruto de la recepción del Acta de Independencia de las Provincias Unidas de Venezuela. Agréguese que el concepto de "provincia", asociado a jurisdicción y territorio, no era desconocido para un jurista del Antiguo Régimen (Vallejo, 1992, pp. 135136), por lo que su uso en la Revolución de Independencia no es de extrañar. En conclusión, a pesar de la fuerza simbólica de estas dos revoluciones (la estadounidense y la francesa) sostenemos que en ellas no se agotó el tema del federalismo y del centralismo.

4 Paine asemeja la revolución francesa y la americana, en clave anti-historicista, afirmando en ambas su capacidad de generar algo completamente nuevo (Paine, 2004, pp. 154-169). Incluso, en su réplica a Burke, considera que la revolución francesa como una continuación de los principios revolucionarios estadounidenses. Recordemos que este debate Paine-Burke, le significó al segundo el apodo de "padre del conservatismo", asunto que consideramos erróneo (Botero, 2008, pp. 598-599).

5 De esta manera no compartimos la tradición historiográfica que cree que las constituciones provinciales fueron copia de la Carta Fundamental de los Estados Unidos (Jaramillo, 1996, pp. 119-120). Como no creemos en la tesis de la copia al modelo estadounidense, preferimos hablar de una recepción (creativa). De esta manera matizaríamos la siguiente afirmación: "Que el modelo viniese de los Estados Unidos, no debe sorprender a los estudiosos de nuestro proceso constitucional. Después del grito emancipador, lo cierto es que hemos alternado en influencias e intentos de trasplante institucionales, sin que pueda decirse, hasta nuestros días, que el país se ha liberado de la manía de copiar constituciones o de injertarlas" (Uribe, 1977, pp. 57 y 68). (art. 4, sección segunda, título primero, constitución antioqueña de 1812), la exigencia constitucional de la elaboración de un código civil y criminal de universal comprensión (art. 10, sección primera, título tercero, constitución antioqueña de 1812) que rigiese preferiblemente para todos los "Estados de la Unión" (art. 55, sección primera, título tercero, constitución antioqueña de 1812$)^{7}$, la ley como expresión de la voluntad general de la nación (art. 6, sección primera, título tercero, constitución antioqueña de $1812^{8}$ ), la división de poderes (art. 4, título segundo, constitución antioqueña de 1812), etc., que dejaban en evidencia un marcado optimismo.

Esta fortaleza que se le da a la ley y el anhelo por el código (aunque estos dos términos

6 Para el caso argentino, Alberdi criticó la intención codificadora de Vélez Sársfield señalando que el federalismo es incompatible con un código centralista y unitario, citando a Estados Unidos como un ejemplo exitoso de federalización sin código (Rabinovich-Berkman, 2006, p. 214). En cambio, durante la primera república de la Nueva Granada, fueron principalmente los textos constitucionales federales los que patrocinaban un código centralista y unitario, sin ver en ello una contradicción con el federalismo, haciendo así una concesión al modelo estatalista-legicentrista.

7 El código era entendido como oposición al viejo derecho común en Francia (Fioravanti, 1998, p. 79). Sobre los antecedentes (revolucionarios e ilustrados) y las implicaciones (racionalistas, universalismo, estatalismo, certeza y optimismo) del ideal de expedición de un código (según el modelo francés) (Thury, 2003, pp. 255-266).

8 "Siendo la ley la expresión de la voluntad general, todas ellas deben ser unas reglas, cuyos objetos sean universales y que no miren a un hombre como individuo, o a una acción determinada; por tanto siempre que la Legislatura se introduzca a decidir en un caso, o sobre una acción particular, traspasa los límites de su poder, y usurpa el Ejecutivo, o Judicial, a no ser alguno de los decretos o actos de magistratura que expresamente se le delegan por su Constitución". El artículo 7 de esta misma sección y título señala: "7. La legislatura tendrá plena y privativa facultad para hacer las leyes en todos los ramos, en todas las materias y sobre todos los objetos de la legislación civil y criminal". El artículo 8 reza: "Su primer y sublime objeto será mantener por medio de leyes sabias la Santa Religión Católica, Apostólica, Romana en toda su pureza e integridad". 
fueran entendidos de manera ambigua, y no necesariamente remitieran a Le Code francés o a un nuevo régimen en sentido estricto) (Petit, 1995 , pp. 49-90) ${ }^{9}$ permiten hablar dentro del constitucionalismo provincial neogranadino de un cierto estatalismo-legicentrismo ${ }^{10}$ con algunos matices diferenciadores de lo entendido por tal en la Europa continental del siglo XIX. Pues bien, la democracia criolla, que se intenta plasmar con la adhesión a los ideales

9 Esta característica no sólo fue neogranadina, pues E. Abásolo (2005, pp. 153-177) defiende la hibridación entre viejo y nuevo régimen en el código de Vélez Sarfield. Súmese que la casación revolucionaria francesa, según Calamandrei (en un estudio de Fairén), provino del Antiguo Régimen -específicamente de la Ordenanza de Blois (1579) (Fairen, 1969, p. 222); y que el propio Código de Napoleón era, según Leclair, formalmente revolucionario y sustancialmente reaccionario: "Mais, révolutionnaire dans sa forme, le Code ne l'était pas quant a sa substance. D'une part, le Code Napoléon est extrêmement réactionnaire, car il reconduit en grande partie le contenu de l'Ancien droit" (Leclair, 2002). Claro está que estas afirmaciones de Calamandrei y Leclair deben ser matizadas, pues la casación revolucionaria obedeció a una lógica estatalista de desconfianza al poder judicial no presente en el Antiguo Régimen -asunto que el propio Fairén reconoce- y Le Code contempló diversas situaciones (en torno a la propiedad privada individual sobre la tierra, la regulación familiar -por ejemplo lo estipulado sobre la disolución de los efectos civiles del matrimonio en caso de muerte civil así como los límites cronológicos de la patria potestad-, las reglas de sucesión, etc.) que son una novedad (agradezco al prof. Carlos Petit sus enseñanzas en este tópico). Sobre las novedades en lo atinente a la propiedad, la familia y el derecho sucesorio, véase Álvarez (1999, pp. 198-204) y Petit (2008). Sobre la continuidad y discontinuidad de instituciones indianas en el derecho sucesorio codificado latinoamericano, véase Guzmán (2008, pp. 31-88).

10 Baste citar como ejemplo la común denominación a la Constitución como el "código sagrado de la Nueva Granada", que denota la fuerte presencia del ideal "codificador" como instrumento de liberalización y la gran carga ideológica en torno a la constitución por la consagración de ciertos derechos políticos. Ver: Sentencia ordinaria (queja), demandante Crus Muñoz, demandado Alcalde de Quirimara (A.H.J.M., documento $6735,1833)$. Además, este ejemplo, también demuestra lo ambiguo del concepto de "código" en el siglo XIX neogranadino. A veces, con este término se aludía a recopilaciones de Antiguo Régimen, otras veces designaba el ideal de un texto moderno con capacidad de derogar texto antiguo y unificar el derecho, etc. liberales e ilustrados, supone, por parte de los súbditos ${ }^{11}$, un apego que va más allá de lo racional (como sería el caso de apelar a los sentimientos "patrióticos") y se torna, además, en un prejuicio afectivo; se tenía que ser patriota nacionalista, revolucionario independentista. Así emergen nuevas autoridades republicanas de las viejas autoridades coloniales (recuérdese cómo los colegios electorales y constituyentes de la primera república estaban conformados en su mayoría por los integrantes de los cabildos) que, en el júbilo de conservadores criollos y liberales convencidos, se instauran como los nuevos detentadores de una soberanía retomada por la abdicación del "Deseado".

Por ello, las nuevas autoridades provinciales, normativamente hablando, se erigen primero en constituyentes y luego en legisladores, reclamando para su producto (la constitución y, luego, la ley) ${ }^{12}$ la subordinación requerida para superar los miedos tanto a un sistema judicial influido

11 ¿Quiénes son los súbditos de una democracia? Para el caso que estudiamos no son otros que los ciudadanos electores, en tanto la democracia plasmada en el 12 se la juega en la representación (sin negar ciertos rasgos de participación, siempre y cuando se trate de un ciudadano en sentido estricto). Así, términos como "vecinos", "nacionales", "ciudadanos objeto de deberes", "ciudadanos objeto de derechos" y "ciudadano elector" varía entre sí. Una crítica al concepto de derechos derivados de la ciudadanía, en tanto supone una restricción de derechos con ocasión del monopolio de lo jurídico por parte del Estado nacional moderno, en Grossi (1995 y 2003). Ahora bien, es Foucault quien recuerda que el hombre moderno es tan súbdito -sujeto- como el de cualquier otra época histórico - política, a partir de mecanismos de control totalizantes (panópticos), pero más imperceptibles (Foucault, 1990; 1992; 1996; 2005).

12 Sería desacertado pensar que las constituciones en el modelo estatalista-legiscentrista carezcan por completo de alguna jerarquía. En el caso de la constitución antioqueña de 1812, que tiene elementos propios del modelo individual así como del estatalista, encontramos algunas garantías de jerarquía constitucional en: el título X, artículo 1, disposiciones generales; el título IV, del poder ejecutivo, artículo 11; el título IV, del poder ejecutivo, artículo 31 ; y el título X, artículo 16, disposiciones generales; entre otros. Esto no quiere decir que ya existía un judicial review, en sentido estricto, en ese entonces. Estas aclaraciones están presentes, en Botero (2007, pp. 91-101). 
por el Antiguo Régimen colonial ${ }^{13}$, como al sistema de privilegios fundados en normas casuísticas y particulares, entre otros aspectos ${ }^{14}$.

De esta forma, se entiende el alegato de un ciudadano que escribió ante un juez, reclamando por el comportamiento del alcalde ordinario de su localidad:

Yo no dudo S. Jues que esto debe suceder asi, pues de otro modo ¿Qué seria de los c. ${ }^{\text {nos }} \mathrm{y}$ principalmente de los pobres como yo puestos $y$ entregados discrecionalm. ${ }^{\text {te }}$ a jueces vengativos, como há manifestado serlo el del partido de mi vecindad? Infaliblem. ${ }^{\text {te }}$ vendriamos a ser victimas de las vengonzosas pasiones de nuestros mandatarios, pero no, afortunadam. ${ }^{\text {te }}$ tenemos leyes justas y majistrados integros que saben hacerlas respetar y obedecer. Por tanto yo espero que U. cumpliendo [con el] encargo q. ${ }^{e}$ le ha confiado el gob. ${ }^{\text {no }}$ experimentará al juez de Quirimará p. ${ }^{a}$ q..$^{e}$ en lo venidero modere sus pasiones, y aprenda a cumplir con sus deberes p. ${ }^{a}$ q. ${ }^{e}$ de este modo, podamos contar nosotros con esa libertad y seguridad personal p. ${ }^{\mathrm{r}}$ quienes hemos hecho tantos $y$ tan grandes

13 La constitución antioqueña de 1815, por ejemplo, exigió al legislador proveer "todas las reformas que demandan las leyes complicadas que hemos adoptado de la España" (art. 11, sección 3 ${ }^{\mathrm{a}}$, título VI), dejando en claro -por lo menos discursivamente- que debe emerger la nueva "ley" republicana para superar el (desprestigiado) viejo régimen español.

14 No puede hablarse de una ruptura absoluta si se compara el sistema judicial colonial con el propuesto en el constitucionalismo provincial (específicamente en el caso antioqueño). Baste para afirmar ello que se crea una "Alta Corte de Justicia" diferente al Supremo Tribunal de Justicia para tramitar "Los recursos extraordinarios que por nuestras leyes se hacían al Soberano, o a los consejeros supremos establecidos en España" (art. 1, sección segunda, título V, constitución de 1812; recursos suspendidos por orden de la constitución de 1815 en el título VI, sección primera, art. 16); permanecen los jueces pedáneos, los tenientes, alcaldes ordinarios, jueces pobladores, capitanes de guerra, alcaldes de la hermandad, etc., como jueces de primera instancia (art. 7, sección tercera, título $\mathrm{V}$, constitución de 1812; que se mantiene en la constitución de 1815 pero bajo la égida de un juez mayor, título VI, sección segunda); se conservan varios recursos coloniales; etc. sacrificios. Es just. ${ }^{a}$ que pido, jurando lo necesario en dro. A ruego de Cruz Muñoz: Pascasio Uribe y Ochoa [Firma y rúbrica] ${ }^{15}$.

También así se explica la consulta que hace el Tribunal del Distrito Judicial de Antioquia que, al encontrar un vacío en la ley penal, se remite a la Corte Suprema de Justicia y esta a la Cámara de Representantes preguntando la pena que debe imponer "a las madres que abandonan en despoblado el cadáver de alguno de sus hijos"16, consulta que deja en claro el ambiente formalista - exegeta de la época que obligaba al Congreso a llenar los vacíos de la legislación ${ }^{17}$, pero este órgano (renunciando a sus atribuciones) remite el caso al Secretario de Estado del Interior, pidiéndole que reúna todos estos expedientes y prepare un proyecto de ley que reforme el código penal poniendo en evidencia el espíritu político hegemónico del ejecutivo.

Así, el derecho del Estado, quien pretende asumir el monopolio de lo jurídico ${ }^{18}$, se teje como institución redentora, aunque no logró nunca tal poder de convencimiento y de legitimidad que aún hoy día se le reclama a las instituciones públicas (García, 2003, pp. 97-98), en especial hacia aquellos que supuestamente eran

15 Sentencia ordinaria (queja), demandante Crus Muñoz, demandado Alcalde de Quirimara, folios 6r y 6v (Documento 6735, A.H.J.M., 1833).

16 A.G.N., Sección República, Fondo Congreso, Legajo 17, Rollo 16, Folio 227.

17 A.G.N., Sección República, Fondo Congreso, Legajo 17, Rollo 16, Folio 233v. Esta reserva legal o referí legislativo, ya existía en la Constitución de Antioquia de 1812 (Título X, artículo 16, Disposiciones generales): "Todos y cada uno de los poderes, jueces y autoridades de la república observarán inviolablemente las leyes, ordenanzas, cédulas y reales órdenes que constituyen los códigos nacionales en todo aquello que no se hallen expresamente derogadas, o sea contrarias a la Constitución del Estado. En caso de duda consultarán al Poder Legislativo" (reiterado en el artículo 10, del título XV, de la Constitución antioqueña de 1815).

18 Incluso los abogados de la naciente república constituyen huestes dóciles en servicio del Estado y su Derecho (Gaitán, 2002, pp. 27-34; Pérez, 2004. pp. 100-113; Wieaker, 1957, p. 59). 
receptores de la legitimidad brindada por el modelo democrático liberal entendido como voto: el ejecutivo y el legislativo.

Resulta así que los modelos teóricos planteados por los liberales de los siglos XVIII y XIX fueron mecanismos institucionales de perseverancia de la democracia representativa que ya se respira en la constitución de 1812. Entonces, la exégesis corresponde a un modelo de control del estatalismo. Por tanto, si la democracia electoral daba legitimidad nacional a órganos políticos colegiados en los cuales se redactarían las leyes, el vehículo encauzador democrático no podía ser otro que la exégesis, pues así se garantizaría que el órgano legislativo se atribuyera para sí la competencia restrictiva de crear normas generales por ser el delegado del soberano (principio de separación de poderes, con respecto al principio de igualdad, art. 4, título III; art. 3, título II, Constitución antioqueña de 1812), siendo entonces el ejecutivo y el juez unos meros aplicadores de la norma (art. 3, título II, Constitución antioqueña de 1812) ${ }^{19}$; todo esto en concordancia con el concepto de seguridad jurídica, entendida como certeza de la ley principio de legalidad- (donde era más importante la certeza que el contenido de la decisión judicial, la firmeza de la sentencia frente a las partes que la justicia de la misma). De esta forma, la exégesis termina siendo una herramienta para encauzar la democracia. Pero cuando emerge la desconfianza generalizada con respecto a la actividad del Estado, que se autocalifica de demócrata, y a su derecho, aparecen fuertes críticas al legicentrismo y a la certeza de la ley, en tanto éstas no garantizaban de modo alguno el ideal democrático porque amarraban la fuente normativa a cuerpos co-

19 Es común en la Europa continental del XIX la desconfianza al juez, por considerarlo una institución del Antiguo Régimen (Fioravanti, 1998, p. 72). No obstante, Fairén, analizando el caso concreto de la Constitución de Cádiz, consideró que durante los primeros tiempos de tal Carta, no había tal desconfianza, pues la observancia de la Constitución y el juzgamiento de los casos de infracción constitucional correspondían, según criterio de las propias Cortes, al poder judicial (Fairen, 1969, pp. 190-194). legiados que no siempre han mostrado lealtad a dicho ideal y mecanizan (e insensibilizan) la labor del operador judicial y del sistema jurídico mismo, asunto que explica Bobbio con las siguientes palabras:

Son varias las razones por las cuales a fines del siglo pasado (XIX) surgió y se desarrolló rápidamente este movimiento contra el estatalismo jurídico y el dogma de la integridad. Pero parece ser que las principales razones fueron las siguientes. Ante todo, a medida que la codificación envejecía (y esto es válido principalmente en Francia) se descubrían sus insuficiencias. Lo que al comienzo fue objeto de admiración incondicional, poco a poco se tornó en objeto de análisis crítico, cada vez más exigente, y la confianza en la omnisciencia del legislador disminuyó o desapareció (1958, p. 214).

En consecuencia, el "derecho por el derecho"20, premisa propia del legicentrismo, en tanto parte de la racionalidad del legislador, llevada a su extremo por el formalismo-formulismo jurídico latinoamericano, dejó de ser una garantía de contención estatal y, por ende, no benefició la actividad liberal. El Estado y el sistema jurídico formalista-formulista, entendido este como un entramado que se intentó autojustificar, pasan a ser criticados por prácticas políticas (a veces caudillistas) por los efectos perversos que generaron, en especial la desobediencia y la consideración del derecho como dominación. De esta manera es que se propusieron ideológica o prácticamente nuevos límites contenedores o encauzadore ${ }^{21}$ del Estado y del sistema jurídico que permitan una refundación del ideal racional - afectivo de la democracia, siendo uno

20 Las críticas a la concepción autojustificativa del Derecho provienen desde el positivismo antiformalista alemán (Ihering, Heck, von Rumelin, Bülow, Ehrlich, etc.) y francés (Gény, Lambert, etc.), que, paradójicamente, fueron adaptadas al formalismo latinoamericano o ignoradas por éste cuando le convenía (López, 2004, pp. 235-340; Botero, 2003, pp. 13-127).

21 Sobre la propuesta de entender al derecho como aparato encausador de los conflictos, más que solucionador (Botero, 2002, pp. 53 - 57). 
de ellos la idolatría personalista, tan propia de los sistemas caudillo-cliente que rigieron desde muy iniciado el constitucionalismo provincial.

El estatalismo-legicentrismo que emerge con el constitucionalismo provincial neogranadino debe ser entendido en los dos planos en que ha sido percibido por la literatura especializada: de un lado, por el estructuralismo y, del otro, por la escuela florentina de historia del derecho. Con respecto al primero (Bobbio, 1958, pp. 8-10; Kelsen, [edición española 1933], 2002) ${ }^{22}$, el estatalismo legicentrismo implica tanto un proceso de monopolio del Estado en la producción jurídica que se inicia generalmente a partir de la exigencia constitucional de redacción de códigos expedidos por el soberano ${ }^{23}$ (art. 10, sección primera, título III, Constitución antioqueña de 1812$)^{24}$, lo que implicó una fuerte revolución del sistema de fuentes, como una interdependencia de la forma de Estado y la forma jurídica.

Este estatalismo- legalismo se verifica como anhelo en la constitución antioqueña de 1812, ya que el Estado, fruto de la nación católica

22 Este último texto es la traducción de un artículo de Kelsen aparecido en 1933, al que Legaz denominó, engañosamente, "Teoría Pura del Derecho".

23 "En el siglo XIX (los códigos) pasan a ser un requisito de la soberanía nacional: todo Estado independiente siente que debía tener, por lo menos, un Código Civil" (Rabinovich, 2006, p. 33). Claro está que dicha pretensión nacionalista no choca con poder tomar el código de otro país, puesto que al ser él fruto del excesivo racionalismo podría sobrevivir a cualquier pueblo $y$ tiempo, tal como efectivamente pasó con la recepción del código en los países hispanoamericanos a lo largo del XIX a partir de la actividad de Bello, Freitas y Vélez Sarsfield, entre otros.

24 Proceso similar, pero no igual, al que sucede en otras latitudes europeas, como es el caso del Reino de las Dos Sicilias (Novarese, 2000, pp. 3-14). Cita esta autora a Mazzacane, para quien que la irrupción del Código en dicho reino se debió a las direcciones políticas generales trazadas por el Congreso de Viena (2000, p. 18), lo cual no es aplicable al caso neogranadino. Por su parte, Mario Rodríguez se refiere al experimento gaditano en Centroamérica como el precursor del positivismo - formalismo latinoamericano (que incluía la mezcla de código, Estado, ley omnipotente, nuevo y viejo régimen, etc.) (Rodríguez, 1984). criolla, torna su legitimidad alrededor del monopolio de la producción jurídica, en términos de ley. La norma que crea el Estado no puede ser otra que la ley general, entendida ella como un derecho del ciudadano y, especialmente, de la nación- pueblo (sección segunda, título primero, Constitución de Antioquia de 1812), siendo un deber su cumplimiento (art. 7, sección tercera, título primero, Constitución de Antioquia de 1812). La ley (especialmente su proceso de fosilización: el código ${ }^{25}$, y sólo ella, es la llamada a ser obedecida, quedando la sentencia y el acto administrativo como meras ejecuciones normativas mas no normas con carácter vinculante propio, pues no son extensión directa de la voluntad general, es decir, de la soberanía. Se regula, de esta manera, el procedimiento de creación de la ley (títulos segundo y tercero, Constitución de Antioquia de 1812) y se prohíben las corporaciones como instituciones creadoras de Derecho (salvo la Iglesia). Igualmente, el Estado se regula por su propia expresión monopolizadora (a pesar de sus concesiones a la religión), a la vez que los derechos de los ciudadanos estarán restringidos y reglamentados por la voluntad general expresada normativamente como ley.

Por su parte, la escuela florentina de historia del derecho $^{26}$ señala, de un lado, la existencia de varios modelos que interactúan entre sí durante el siglo XIX y, del otro, cómo la modernidad jurídica (especialmente el modelo estatalistalegicentrista) se construyó a partir de mitos o dogmas. Entre estos modelos encontramos fundamentalmente el individualismo, el historicismo y el estatalismo. Si bien, el modelo indi-

25 Claro está que no podemos caer en el error de reducir el concepto "ley" al de "código", por tanto los análisis y las críticas a éste no se pueden extender, sin más, a aquella. (Simon, 2009, pp. 371-394).

26 Especialmente Grossi, 1995 y 2003; Fioravanti, 1998; Narváez, 2005). No obstante, en torno al sentir de esta escuela sobre el legicentrismo, el prof. Thomas Simon (Universidad de Viena) hace un matiz muy importante: el concepto de ley en el siglo XIX no fue homogéneo, especialmente no pueden igualarse los análisis sobre el legicentrismo codificador (especialmente civil) con los que se hagan sobre la ley administrativa (Simon, 2009, pp. 371-394). 
vidualista busca una ruptura con el Antiguo Régimen, se inicia con el iusnaturalismo y las teorías del Estado de naturaleza, buscando pasar de la sociedad de privilegios a la sociedad de la ley (Fioravanti, 1998, pp. 36-37), respaldando un legicentrismo, como motor regulatorio en defensa de los derechos del individuo, basado en diversos mitos que reducen la complejidad y la incertidumbre del ciudadano:

Una ley -la de los modernos- que se concreta más en un acto de voluntad que de conocimiento. Ocasionalmente, puede ser redactada por estudiosos y tener un gran contenido sapiencial, pero su fuerza la obtiene no de su contenido sino de su procedencia del máximo órgano del poder político. Que después, artificiosamente se identifique la asamblea legislativa con el único representante de la voluntad popular y la ley con la única expresión de la voluntad general, son sólo presunciones absolutas y verdades axiomáticas acuñadas por una hábil estrategia de política del derecho (Grossi, 2003, p. 17).

Dentro del individualismo, Francia es mirada como el modelo a seguir (con su revolución social y el aumento de un instrumento colectivo) y ya no Inglaterra (con su gobierno limitado y tímido en la lucha contra el privilegio) (Fiorovanti, 1998, p. 37). Además, el modelo individualista es considerado un fruto de las antítesis entre Estado e individuo y contractualismo (que en una de sus vertientes fortalece de gran manera el Estado)-historicismo. Pero el modelo individualista limita al Estado -en construcción- con la presunción de libertad y la exigencia de previsión legislativa (así como de poder constituyente), por lo que las libertades no son creación del Estado sino que tienen su fundamento en un pacto social (previo a la existencia del Estado) que reconoce unos derechos naturales (Fiorovanti, 1998, p. 41). Ahora bien, solo observando la constitución del 12 desde este modelo, tendríamos que algunos de sus elementos bien se adecuan a él, en lo atinente a la consagración del pacto como causa del Estado (preliminares de la constitución), así como la estipulación de derechos de origen divino que se constituyen en garantías del ciudadano (no tanto del individuo) frente al Antiguo Régimen, y, además, por su carácter superior frente al Nuevo (sección segunda, título primero, art. 1). Incluso, desde la observación a las teorías de Rousseau (tan de boga en el constitucionalismo provincial neogranadino), tenemos que, al ser este ubicado por la literatura (Fiorovanti, 1998, p. 43) a caballo entre el individualismo y el estatalismo, el constitucionalismo antioqueño si bien presenta elementos del modelo individual, no deja de lado concepciones estatalistas que, a la larga, terminan dominando ya no solo el constitucionalismo sino la propia cultura constitucional provincial y nacional.

Otro ejemplo de individualismo en la constitución antioqueña lo representa el hecho de que frente al privilegio y al particularismo se oponen derechos individuales naturales y soberanía nacional $y$, al igual que el constitucionalismo revolucionario francés, tiene como novedad la de hacer aparecer de improviso sobre la escena, en su autonomía, una sociedad civil unificada en la perspectiva de la voluntad política constituyente, como pueblo o nación (Fiorovanti, 1998, p. 61).

El individualismo, pues, busca como garantía de las libertades individuales negativas, un Estado limitado a partir de la supremacía constitucional (lo que conlleva al castigo de las infracciones cometidas contra la Constitución por parte de la Ley -con la nulidad de esta, por ejemplo- $y$ por parte de los funcionarios $y / o$ ciudadanos -con sanciones penales para estos, por decir algo-) y de la rigidez constitucional (sometiendo el proceso de reforma constitucional a unas especificidades procedimentales más complejas que las previstas para la aprobación de las leyes, en tanto se diferencia el poder constituyente del poder constituido), cuestión que no puede pasarse de largo. Ha sido común interpretar que la supremacía constitucional tiene su fundación en el constitucionalismo es- 
tadounidense ${ }^{27}$; sin embargo, las constituciones que estudiamos (Acta de las Provincias Unidas de la Nueva Granada, Constitución de Antioquia, etc., así como varios proyectos de constitución redactados por liberales españoles ${ }^{28}$ ) no dudan en regular el proceso de formación de la Ley, muchas veces con procedimientos diferenciados para la reforma constitucional, y establecer mecanismos de sanción al infractor de la Constitución que dan a entender, por lo menos en el campo del discurso jurídico formal, un ánimo de diferenciación entre Constitución y Ley.

En el caso de la constitución antioqueña, que es un buen ejemplo del constitucionalismo independentista hispanoamericano, es común la alusión a expresiones tales como arreglándose fielmente a la constitución» (art. 38, sección primera, título III), que dejan en claro cómo la Constitución es entendida, en dicho texto, en clave estatalista-legicentrista, puesto que a diferencia del modelo individual, la superioridad y la rigidez constitucionales no son tanto en lo tocante con unos derechos o libertades (que al ser reconocidos como propios del derecho natural van más allá del reconocimiento que de ellos hace la Constitución provincial) que así quedan garantizados frente a la acción del Estado (garantía negativa), ni en lo que respecta con unos contenidos considerados como superiores (que en caso de ser transgredidos por la Ley esta podría ser considerada nula por aspectos más allá de los procedimentales), sino

$27 \quad$ El producto del constituyente estadounidense aparece como un conjunto inviolable de reglas (rigidez y supremacía constitucional como tutela de libertades), que es una mezcla del higher law así como del contrato social, lo cual queda afincado, entre otras decisiones judiciales, con el juez Marshall en 1803 (Marbury Vs Madison). Empero, esta famosa sentencia no fue la primera en esta línea (Botero, 2007).

28 En la Constitución de Cádiz observamos un fenómeno similar de defensa de la supremacía constitucional a partir del procedimiento de "infracciones constitucionales" (Lorente, 1988; Fairen, 1969, pp. 173-194) aspecto en el cual los diputados americanos mostraron una gran preocupación, con el fin de hacer observar que el texto constitucional no podría ser violado bajo ningún concepto (Berruezo, 1986, p. 310). más bien en lo que toca al procedimiento de creación de la ley y a la contención normativa del Estado mismo y de sus funcionarios, como sucede, por ejemplo, con el establecimiento de procedimientos de sanción a quien no obedezca la Constitución (artículo 31, sección primera, título IV, de la carta antioqueña de $\left.1812^{29}\right)^{30}$.

En consecuencia, no puede negarse que la rigidez orgánica y la supremacía de la Constitución son una "garantía negativa» de los ciudadanos frente al Estado, pero está escrita, en el caso que nos ocupa, en una lógica inversa a la que se observaría en un constitucionalismo dogmático moderno y meramente individualista ${ }^{31}$.

En cambio, el historicismo, para la garantía de las libertades individuales, lo intenta por medio

29 El Presidente deberá velar en la observancia de la Constitución y de las leyes: así estará a la mira de las operaciones de todos los jueces, tribunales y empleados públicos para que cada uno llene las obligaciones de su destino. En el caso de infracción notoria denunciará los miembros de los tres poderes a la Cámara de los Representantes, para que haga la debida acusación ante el Senado; y a los demás funcionarios a sus respectivos jueces para el castigo y reforma correspondientes, pues el Presidente por ningún motivo se mezclará en las atribuciones del Poder Judicial.

30 Existe un punto de contacto entre este artículo con lo estipulado en los artículos 372 y 373 de la Constitución de Cádiz: un cuerpo colegiado soberano (Congreso y Cortes, respectivamente) que por medio de un procedimiento supervisa las actuaciones de los empleados públicos; pero se diferencian dichos textos en que la constitución antioqueña pone en cabeza del Presidente la función de velar por la observancia de la constitución, mientras que la gaditana no duda en establecer dicha responsabilidad en las Cortes (Lorente, 1998, pp. 21-35).

31 En conclusión, se alega que en las constituciones provinciales existe cierta visión diferenciadora entre la Constitución y la Ley, lo que podría dar a entender que se está ante una supremacía y rigidez constitucionales. Pero esta afirmación debe ser matizada si se tiene en cuenta el modelo estatalista-legicentrista presente en estas Cartas, de manera tal que dicha supremacía y rigidez constitucionales no se pueden equiparar a las establecidas por la dogmática constitucional contemporánea y por el modelo individualista al que alude Fioravanti. Esto, por demás, pone en evidencia la importancia de matizar como función de la iushistoria. Debo agradecer al profesor Ignacio Fernández Sarasola (Universidad de Oviedo) por sus sugerencias y comentarios en torno a estos párrafos. 
de una jurisprudencia mesurada fundada en la costumbre judicial. Este modelo, con respecto a las libertades positivas, busca que estas sean accesibles gradualmente, sin rupturas que causan inestabilidad (como las asambleas constituyentes), siendo así accesorias y funcionales a las libertades negativas (Fioravanti, 1998, p. 44). Pero para el individualismo, en lo que toca a las libertades positivas, no tienen carácter accesorio con las negativas, aunque puede generar un acto de voluntad del poder constituyente que debilite una unidad política, con lo que el individualismo contractualista conllevaría, de un lado, a un fortalecimiento del poder estatal que garantice los derechos especialmente en momentos de transición, pero de otro, a un movimiento jacobino de manifestación del poder constituyente con su consecuente proceso de inestabilidad política estatal.

Por otra parte, teniendo presente que existen elementos del modelo individualista en el constitucionalismo provincial, esto no es óbice para afirmar que el modelo estatalista se termina cimentando como la propuesta política central en el mismo, en tanto reacción al contractualismo puro que bien puede degenerar en el jacobinismo, tan odiado por los criollos, y como forma de asumir las élites conservadoras $y$ tradicionales en una estructura de poder que garantizaría en nombre de la institución el juego de poder recién adquirido. Según el estatalismo, para la literatura de la escuela florentina, no existe sociedad antes de la constitución del Estado (Fioravanti, 1998, p. 48), por lo que la nación nace con y gracias al Estado. El contrato es para el derecho privado, razón por la cual no hay un contrato social. El pacto es de decisión política y esa masa amorfa de súbditos del rey pasa a ser ciudadanos de un Estado que, a lo largo del siglo XIX, tiene como principal misión la construcción de nación debido a la carencia de una mitología nacional más allá de los ideales del poder político ${ }^{32}$.

32 Al respecto, véase las razones que da Urrego (marzo de 1998, pp. 10-18). En este texto el autor afirma la inexistencia histórica de un mito de nacionalidad colombiano unificador (p. 12).
La libertad positiva no es natural expresión de un soberano precedente y autónomo sino expresión del Estado; el ciudadano (católico, en el caso hispanoamericano), con el voto, ejercita una función de designación de los miembros de la organización estatal (Fioravanti, 1998, p. 51), y es esta quien determina el contenido mismo de las libertades que gozarán los súbditos en general, por lo que el Estado mismo no reconoce límites por fuera de él, quedando en sus manos no solo la regulación de los ideales trazados constitucionalmente (entendida como ley de rango superior) sino de darles materialidad propia sin mayor ligazón con ella, salvo en el campo orgánico (estructura del gobierno y procedimiento de creación de la ley).

Obviamente, no existen modelos puros, y elementos del estatalismo, del individualismo y del historicismo, que encontraremos en las constituciones de independencia. Pero en lo que se quiere llamar la atención es que estas constituciones no dejan de sembrar el germen de un proceso estatalista-legicentrista, que se verá mayormente acentuado por la praxis política que poco a poco evoluciona por el vaivén de los hechos en una república centralista y unipersonal, asunto que puede mostrarse con el siguiente ejemplo. Según el modelo individualista de la Declaración de los Derechos del Hombre (incorporado al constitucionalismo provincial, art. 33, sección segunda, título I, Constitución de Antioquia de 1812) hay una jerarquía del principio de libertad, que se expresa en los demás principios (tipicidad de los delitos, prohibición de analogía en materia penal, etc.) (Fioravanti, 1998, pp. 61-62); sin embargo, el constitucionalismo provincial considera la propiedad como un derecho de carácter natural y divino, de mayor reforzamiento que la libertad en sí misma, al punto de que la libertad se predica más del propietario, para el cumplimiento de su tarea de conformante (al elegir o ser elegido) de la nación y del soberano legislador (art. 3, título II, Constitución antioqueña de 1812).

En conclusión, el legicentrismo del constitucionalismo provincial neogranadino es el pun- 
to sobre el cual la revolución independentista media entre individualismo y estatalismo puro, convirtiéndose la ley en un valor en sí y que terminará por legalizar las juntas ya constituidas como legisladores (con lo que se obvia el problema de la relación poder legislativo-constituyente al que alude Fioravanti (1998, p. 65), para fundar esa relación ya mencionada entre un derecho considerado en momentos de júbilo como redentor y al poco tiempo como opresor (dialéctica común en todo el XIX colombiano [García, M., 2003 y 2006]), y que trajo como consecuencia una crítica al poder constituyente directo, permitiendo una representación unitaria del cuerpo político (autonomía de la clase política frente a la sociedad civil para poder así trascender al sentir único del pueblo o de la nación) (Fioravanti, 1998, p. 67) que no dejará de ser rechazado con el término "partido» al que aluden tan peyorativamente tanto patriotas (Bolívar, los presidentes y gobernadores de Antioquia, etc.) como españoles en proceso de pacificación militar (Morillo).

Claro está que los criollos no tenían conciencia de la creación de una constitución estatalista, pues los modelos de lectura del proceso constitucional son dados a posteriori por el historiador del Derecho. No obstante, ese constituyente colegiado (juntas de gobierno o cuerpos electorales) creyó que con la redacción de la constitución provincial y la promulgación de las instituciones ya comentadas, se lograba varios propósitos: (i) frenar el peligro jacobino de inestabilidad política y de fuerte voluntarismo; (ii) respaldar unos derechos que legitimaban la acción política fundamentalmente de una casta, contemplándose el voto restringido como el mecanismo de aceptación (tácita o expresa) del nuevo estado de cosas; iii) consolidar la alianza entre buena parte de los criollos con el Estado motivada, además, por la visión limitada de las libertades políticas, el alto grado de cohesión y solidaridad entre los miembros de la élite y el miedo a una guerra de castas (Lynch, 1987, pp. 116-117).

Pero esta tendencia estatalista que nace con el constitucionalismo provincial es común en la
Europa continental (Lynch, 1987, pp. 71-72), aunque con orígenes algo diversos. En consecuencia, no podría hablarse de un proceso legicentrista - estatalista en contra de la tendencia europea, pero sí existe una fuente del mismo con aspectos diversos y con consecuencias similares, como lo es la debilidad de las partes dogmáticas de las constituciones (como las provinciales de independencia y la francesa revolucionaria) (Lynch, 1987, p. 74) ${ }^{33}$.

Sin embargo, ante la pregunta de cómo evitar que el legislador sea un déspota, la respuesta es simple: lo que haga es justo pues encarna la voluntad de la nación ${ }^{34}$. Entonces, no se trata de limitar al legislador sino de fortalecer su autoridad, con lo que se estipula el deber ciudadano (entendiendo por tal de la manera más amplia posible) de obedecimiento de la ley en tanto expresión soberana: «Las obligaciones de cada uno para con la sociedad consisten en defenderla, en servirla, y en vivir sumiso a las leyes y a la Constitución; y en respetar a los funcionarios públicos, que son sus órganos» (art. 3, sección tercera, título I, Constitución de Antioquia de 1812) ${ }^{35}$.

Por tanto, es válido decir que el constitucionalismo provincial participa activamente desde su propio programa normativo en la creación del Estado liberal, en su forma latinoamericana, donde el centro de la actividad está anclado en

33 Por ejemplo, en el reino de las Dos Sicilias, la codificación se instaura (y con él irrumpe una visión estatalista - legicentrista) sin la presencia de una constitución garantista de las libertades públicas. Es más, el proceso de codificación (en este caso la penal) fue pretexto para frenar las innovaciones ilustradas: "ll nuovo clima politico determinatosi nel Regno delle Due Sicilie si concretizzava, infatti, significativamente, nell'emanazione di una legislazione penale eccezionale, frutto di una cultura del sospetto, che vanificava, almeno parzialmente, i resultati raggiunti attraverso la codificazione e, al contempo, impediva la maturazione di impulsi innovativi di matrice giusnaturalistica e illuministica" (Novarese, 2000, p. 14).

34 Asunto que Bobbio denomina "positivismo ideológico" o "formalismo ético" (Bobbio, 1993, pp. 139-241).

35 "Todo ciudadano llamado, o aprehendido en virtud de la ley, debe obedecer al instante, y se hace criminal por cualquiera resistencia" (art. 7, sección tercera, título I). 
el estatalismo - legicentrismo y en una constante crítica al modelo progresista de los derechos (que, sin embargo, dio legitimidad discursiva en ciertos momentos al proceso independentista), por el miedo a la inestabilidad y al voluntarismo jacobinos que se creía estaban asociados a las tesis más revolucionarias, sumado a la desconfianza frente a una rebelión de castas que afectara la nueva composición del poder.

No aparece, pues, en este modelo liberal latinoamericano, un Estado mínimo, con contenciones fuertes para permitir el libre desarrollo de las libertades de los ciudadanos, sino, por el contrario, se vislumbra la intención constitucional de dar origen a un Estado (casi panóptico) con intenciones claras de construcción de la identidad nacional desde lo político, y con el ideal de una sola voluntad de querer que elimine las facciones y las disidencias que quedarían siempre resueltas en el seno del omnipotente legislativo que es el legitimado por ser el depositario de la soberanía, es decir, efecto directo del contrato social. De esta forma, se plantea normativamente un Estado liberal de Derecho; Derecho porque se busca la tutela de los individuos y de la sociedad, y Estado porque busca defender las instituciones políticas, con lo que debería producirse la separación sociedad y Estado para evitar que una dirigiera a la otra (Fioravanti, 1998, p. 103) separación que se terminó por instaurar gracias, entre otras cosas, a la eficacia simbólica y al síndrome normativo propios de la normativa del naciente Estado, así como por la diferencia de los intereses a regular entre la una y el otro.

Esta separación sociedad - Estado provoca la pérdida paulatina del derecho constituyente, y se prefiere así, por parte de los liberales neogranadinos del XIX (que vieron el nacimiento de su concepción de Estado durante ese caótico proceso hiperconstitucional), el término nación, en tanto es más estable que el de atomismo revolucionario (pueblo donde cada individuo es soberano) (Fioravanti, 1998, p. 105), siendo este último muy útil en momentos aciagos de guerra contra el peninsular pero que una vez necesitada la construcción del «imperio de la ley» parecía ponerlo en peligro. Así, pueblo y nación, términos intercambiables en la revolución independentista americana, pasan a un proceso de diferenciación que nace en el constitucionalismo provincial para afirmarse, bien entrado el siglo XIX, que la nación es una entidad socio histórica (Fioravanti, 1998, p. 105) con lo cual está obligada a tener en cuenta la herencia, por lo que no puede decidir ex novo (Fioravanti, 1998, p. 106).

El individualismo, ya tenido a menos en las constituciones provinciales, va perdiendo aún más su eficacia con la emergencia gradual, durante ese inicial proceso hiperconstitucional neogranadino, de interpretaciones políticas estatalistas e historicistas, con el fin de proteger a las instituciones públicas en proceso de robustecimiento (especialmente luego de 1819) del poder perturbador de una constitución garantista, leyéndose así que los derechos están en el Estado y no en la Constitución (Fioravanti, 1998, p. 107), por lo que la supremacía constitucional queda reducida a su parte orgánica y a servir de instrumento de legitimación de los poderes públicos (así se explica cómo en la Colombia del XIX, los grandes cambios de poder político implicaron rápidamente la redacción de una nueva constitución). El código y la administración pública (que remiten a conceptos de «ley» diferentes pero no excluyentes en su aspectos institucional [Simon, 2009]) pasan de girar en torno a la constitución (como era el proyecto inicial) para hacerlo en torno al Estado-Ley. Con el código, por ejemplo, se espera surja el derecho estatal como fiable, certero y estable, garantizando una aplicación certera y estable de los derechos subjetivos, cosa que solo podría verificarse por instancia diferente a la constitucional: «La tutela de los derechos garantizados por la constitución se sustituye por la certeza del derecho garantizado por el código y la ley, por el derecho positivo del Estado" (Fioravanti, 1998, p. 110). Ya los jueces, según el ideal liberal latinoamericano, no deberán aplicar el derecho programático de las declaraciones de derechos sino el derecho cierto del 
código que es emitido por el soberano; ideal, por cierto, que se mantiene de mil y una formas (en la enseñanza universitaria, en la nominación como código a recopilaciones españolas, etc.), a pesar de la inexistencia estricta del código durante buena parte del XIX (Petit, 1995, pp. 49-90) ${ }^{36}$.

Empero, en este ambiente normativo, donde se consolida el derecho administrativo como potestad originaria soberana del Estado ${ }^{37}$, surge la administración pública moderna como una excepción a la universalidad del código civil. En consecuencia, el Estado, al no ser un particular, no está sometido al código civil sino a un derecho positivo estatal especial (Fioravanti, 1998, p. 113).

Con el proceso constitucional neogranadino durante el siglo XIX, las declaraciones de derechos que empiezan a ser enunciadas sin gran contundencia o por efectos simbólicos de legitimación de la revolución en un ánimo de ligar la independencia con la Revolución Francesa, terminan despachándose como meros programas político - filosóficos que requieren, para su

36 Es interesante analizar cómo la "ausencia del código" durante buena parte del siglo XIX estuvo acompañado de: 1) Un fuerte ánimo a favor de la codificación como forma de superar las recopilaciones propias del Antiguo Régimen, 2) La constante aplicación de la legislación española en los procesos judiciales, en especial de las Partidas, durante todo el siglo XIX (Ots, 1974, pp. 173-182), 3) El creciente estatalismo y formalismo en los discursos jurídico-políticos, y 4) La denominación como código a diversas recopilaciones granadinas. Al respecto estamos en la construcción de un texto que dé cuenta de estos asuntos a lo largo del siglo XIX, con base en expedientes judiciales antioqueños.

37 Si bien es cierto que el derecho administrativo recibió herencias (continuidades) tanto coloniales (Malagón, 2007) como decimonónicas (recordando lo escrito por el prof. Petit: "Es suficiente recordar que la matriz doméstica de la Administración en el Estado liberal, a través de la vía dicha 'sorprendente' de la ciencia de policía, trasvasó al joven derecho administrativo principios y modos de actuar característicos de la vieja potestad paterna" (Petit, 2005, pp. 237 - 279), no puede desconocerse un rol importante a la recepción creativa moderna del derecho administrativo europeo (especialmente el francés). Se trata pues, de un juego de continuidades y discontinuidades, es decir, de temporalidades. ejercicio efectivo, actos soberanos de autolimitación emitidos por el propio Estado, es decir, la ley. La soberanía nacional, entonces, es entendida como autonomía de las instituciones políticas de una entidad previa (el pueblo), con lo que este sólo podrá gozar de unos derechos consagrados constitucionalmente, si media un acto normativo emitido por el soberano, que es elegido por voto indirecto o censitario, siendo el voto el principal medio que da el Estado en su configuración de república, pero al que solo algunos tienen acceso, ya que los criollos se consideraban a sí mismos como el «pueblo» (Jaramillo, 1996, pp. 122-123).

A pesar de la exigencia de manifestaciones soberanas para la existencia normativa de los derechos, en el ámbito antioqueño subsistirán dos manifestaciones como fundamentales: ser tratados conforme a las leyes del Estado en un plano de igualdad y el de respeto a la propiedad. El Estado, al normativizarse, debía ser juzgado por sus actos contra la ley (derecho del individuo), pero no podía ser juzgado como un particular; de allí que el derecho administrativo se diferenciaría del código civil y llegaría a tener una identidad propia (incluso, con el tiempo, una jurisdicción propia) diferente a la ordinaria como emanación del proceso hiperconstitucional, fuente del Estado liberal neogranadino.

Pero se había dicho con anterioridad que el centralismo - legicentrismo no sólo fue respaldado por el programa normativo del constitucionalismo provincial en el período hiperconstitucionalista, aunque de manera incipiente respecto de lo que sería más adelante. El impulso para la consecución del modelo estatal liberal latinoamericano fue, fundamentalmente, el proceso de centralización y personalización del poder que se vivió durante la gesta independentista y en los años inmediatamente siguientes.

El poder constituyente que, efectivamente, fue ubicado en las juntas de gobierno erigidas durante el vacío de poder de 1808 , pasó a ser depositario de la soberanía por medio de las cartas constitucionales que ellos redactaban, 
constituyéndose en las primeras legislaturas, sin posibilidad de una transición a cuerpos más elaborados (como el senado y la cámara planteados en la Constitución antioqueña del 12), por la reconquista española. Pero las juntas de gobierno criollas que instauraron el constitucionalismo provincial tuvieron que enfrentar la emergencia de un nuevo liderazgo político que jugaría un rol central en la conformación regional durante la guerra de independencia neogranadina hasta la actualidad: el caudillismo y el subjetivismo político.

El proceso constituyente, anclado a cuerpos colegiados $^{38}$, conformados por criollos, con fuertes sentidos conservadores y con antecedentes claros en los cabildos, pasa poco a poco y auspiciado por la crisis del modelo federal con posterioridad a la reconquista de Morillo, a depender de personalidades (generalmente caudillos militares) y de procesos políticos dictatoriales. Lo colegiado pierde terreno ante lo unipersonal en materia política. Así, frente al constitucionalismo, se fue delineando paulatinamente una mentalidad política pragmática que debía terminar justificando la acción del agente monocrático (como la dictadura) de quien tuviera fuerza y autoridad para asegurar el orden y la paz, resolviendo autoritariamente (pero camuflado en un discurso legal) los conflictos concretos surgidos de los intereses

38 Fue común en el primer constitucionalismo hispanoamericano considerar que el mejor gobierno era el colegiado, pues suponía un control inter pares, a la vez que se articulaba con lo adoptado políticamente en la España de ese entonces. Esto explica la importancia de las juntas de gobierno, de los colegios electorales y de los cabildos en este período, desde Argentina hasta México. Al respecto dice la Orden de creación de Juntas Provinciales en el Río de la Plata del 10 de febrero de 1811: "Esta clase de gobierno ofrecerá magistrados poderosos, pero esclavos de las leyes, ciudadanos libres, pero que saben que no hay libertad para el que no ama las leyes, virtudes civiles, virtudes políticas, amor de la gloria, amor de la patria, disciplina austera, $y$ en fin hombres destinados a sacrificarse por el bien del estado" (trascrito en Gardinetti, 2006, p. 52). Para el caso venezolano, López llama la atención sobre la importancia de los cuerpos colegiados locales en la primera república, lo que le permite afirmar la continuidad del régimen colonial (López, 2004). y las expectativas en pugna (Romero, 1985, p. XXVIII).

Surge, pues, un realismo político en la actividad política y constitucional al finalizar la segunda década del siglo XIX, que reemplaza el delicado corte republicano - colegiado del constitucionalismo provincial y ratifica el modelo legicentrista - estatalista donde ya no era necesario usar la máscara de «Fernando VII» como legitimidad de la toma del poder sino más bien la autoridad derivada de la eficacia que se imponía sobre el discurso a partir de la fuerza de quien lo emitía.

En este ambiente, es que toman fuerza las teorías centralistas, inicialmente con Nariño y luego de la mano de Bolívar, lo que amarra aún más el Estado como una estructura fuerte, burócrata, centrada bajo cuerpos políticos dependientes efectivamente de la voluntad de algunos individuos que ya no actuaban con convicción de casta, y que veían la estructura pública y la ley como los destinatarios de su querer. La ley, objeto de codicia del voluntarismo político centralista, pasa a un terreno central en tanto es la forma con que se reviste el querer del dirigente político (por ende, el discurso legicentrista tan auspiciado desde el modelo postindependentista) y el Estado como premio de consolidación del detentador del poder real de turno (que explica la reivindicación como fuerza en pos de la construcción de Estado en los movimientos armados que se disputaban el poder en las guerras civiles del siglo XIX).

En conclusión, el poder judicial neogranadino, desde el período hiperconstitucional, fue reducido rápidamente al legislador debido a que este último era el depositario de la soberanía y era integrado por los criollos independentistas. Pero a la larga, las relaciones entre este omnipotente legislador, según el programa normativo, entran en conflicto con las pretensiones caudillistas y subjetivistas que se arropan en el ejecutivo, produciendo serios problemas entre estos dos órganos a lo largo del siglo XIX, y que no deja de tener consecuencias en la concep- 
ción legicentrista y estatalista que lo hace algo diferente al estatalismo europeo del siglo XIX.

Se explica así como la ley, que debía ser según el constitucionalismo provincial la manifestación del poder soberano, termina siendo una expresión de la voluntad política de ciertos individuos que pueden arroparse el querer del Estado, exigiéndose una ciega obediencia al mandato legal a la vez que pone de manifiesto la separación Estado - Sociedad, con lo cual en ciertos momentos para un sector social la ley decimonónica neogranadina es salvífica, y para el sector opuesto en la lucha por el poder un retroceso inadmisible, con lo que el derecho se la juega en la ambivalencia ya puesta en evidencia: la obediencia y la desobediencia. Falta agregar que el modelo legicentrista, en crisis práctica constante en el juego antes descrito, entra en una crisis discursiva aún mayor cuando la misma ley aparece (luego de la I Guerra Mundial) ya no como el fruto de una voluntad política o como la expresión de una unidad histórica de la nación, sino de una mayoría vencedora en el parlamento. Surge la necesidad de limitar al legislador, con lo cual «la constitución como norma fundamental de garantía y la constitución como norma directiva fundamental de las revoluciones volverá de esta manera a vencer» (Fioravanti, 1998, p. 125).

\section{REFERENCIAS}

Abásolo, E. (2005). ¿Expresiones del Ius Commune en la apoteosis de la codificación? Las notas de Dalmacio Vélez Sársfield o de cómo un código decimonónico pudo no ser la mejor manifestación de la cultura del código. Prudentia Iuris (Revista de la Facultad de Derecho de la Pontificia Universidad Católica Argentina), 60, 153-177.

Álvarez, C. (1999). Lecciones de historia del constitucionalismo. Madrid: Marcial Pons, 198-204.

Berruezo, M. T. (1986). La participación americana en las Cortes de Cádiz: 1810-1814. Madrid: Centro de estudios constitucionales.
Bobbio, N. (1958). Teoría general del Derecho. Trad. Eduardo Rozo Acuña. Bogotá: Temis.

Bobbio, N. (1993). El Positivismo jurídico. Madrid: Debate.

Botero, A. (2002, Agosto-Septiembre). La resolución de conflictos en el ámbito de la criminología. Revista de Derecho Penal, 32, 53 - 57.

Botero, A. (2003). Diagnóstico de la eficacia del Derecho en Colombia y otros ensayos. Medellín: Señal Editora y Fondo Editorial Biogénesis.

Botero, A. (2007, Septiembre-Diciembre). Haciendo memoria de la defensa judicial de la constitución. Pensamiento Jurídico: Universidad Nacional de Colombia, 20, 91-101.

Botero, A. (2008). La pluralidad de significados del conservatismo: ¿desde dónde hablamos? En Domínguez, E. (Eds.), Historia de las ideologías políticas: proyecto Ágora. (p. 595-613). Medellín: Canal U y Universidad EAFIT.

Busaall, J. B. (2008). Révolution et transfert de droit: la portée de la Constitution de Bayonne. Historia Constitucional (revista electrónica), 9, Disponible en: http://hc.rediris.es/09/index.html, especialmente parágrafo 44 .

Fairen, V. (1969). Temas del ordenamiento procesal. Tomo I. Historia. Teoría general. Madrid: Tecnos.

Fioravanti, M. (1998). Los derechos fundamentales: apuntes de historia de las constituciones. Trad. Manuel Martínez Neira. Madrid: Trotta.

Foucault, M. (1990). Vigilar y castigar: nacimiento de la prisión. Trad. Aurelio Garzón del Camino. México: Siglo XXI.

Foucault, M. (1992). Microfísica del poder. Madrid: La Piqueta.

Foucault, M. (2005). Las palabras y las cosas: Una arqueología de las ciencias humanas (1966). Trad. Elsa Cecilia Frost. Buenos Aires: Siglo Veintiuno. 
Foucault, M. (1996).Tecnologías del yo. Trad. Mercedes Allendesalazar. Barcelona: Paidós - I.C.E.

Fraga, M. (1977). Prólogo. En Uribe, D. Las Constituciones de Colombia. Tomo I. Madrid: Ediciones Cultura Hispánica.

Gaitán, J. (2002). Huestes de Estado. Bogotá: Universidad del Rosario.

García, E. (1964). La administración española. Madrid: Instituto de Estudios Políticos.

García, M. (2006). El derecho como esperanza: constitucionalismo y cambio social en América Latina, con algunas ilustraciones a partir de Colombia. En Uprimny, R., Rodríguez, C. \& García, M. (Eds.) ¿̇usticia para todos?: Sistema judicial, derechos sociales y democracia en Colombia. (p. 201-233). Bogotá: Norma.

García, M. (2003). Apuntes sobre codificación y costumbre en la historia del derecho colombiano. Precedente: anuario jurídico. Cali: Universidad Icesi.

Gardinetti, J. P. (2006). La revolución criolla: surgimiento y desarrollo de las instituciones argentinas en la etapa revolucionaria (1810-1815). La Plata: Universidad Nacional de la Plata.

Grossi, P. (1995). L'ordine giuridico medievale. Roma - Bari: Laterza.

Grossi, P. (2003). Mitología jurídica de la modernidad. Trad. Manuel Martínez Neira. Madrid: Trotta.

Guzmán, A. (2008). La pervivencia de instituciones sucesorias castellano-indianas en las codificaciones hispanoamericanas del siglo XIX. En De La Puente, J. \& Guevara, J. A. (Eds.). Derecho, instituciones y procesos históricos. Tomo III. (p. 31-88) Lima: Instituto Riva-Agüero y Pontificia Universidad Católica del Perú.

Jaramillo, J. (1996). El pensamiento colombiano en el siglo XIX. Bogotá: Planeta.
Kelsen, H. (2002). La teoría pura del Derecho (edición española 1933). Trad. Luis Legaz. México: Colofón.

Leclair, J. (s.f). Le Code civil des français de 1804: une transaction entre révolution et réaction. Revue juridique Thémis, 36, 1.

Levaggi, A. (2007). Confederación y federación en la génesis del Estado argentino. Buenos Aires: Facultad de Derecho de la Universidad de Buenos Aires.

López, A. E. (2004). Viejas instituciones para una nueva república: El caso de Venezuela (18101830). Revista de Historia del Derecho, Buenos Aires, 32, 135-148.

López, D. (2004). Teoría impura del Derecho: la transformación de la cultura jurídica latinoamericana. Bogotá: Universidad de los Andes, Legis y Universidad Nacional de Colombia.

Lorente, Marta. (1998). Las infracciones a la Constitución de 1812. Madrid: Centro de Estudios Constitucionales.

Lynch, J. (1987). Hispanoamérica 1750-1850: Ensayos sobre la sociedad y el Estado. Trad. Magdalena Holguín. Bogotá: Universidad Nacional de Colombia.

Malagón, M. A. (2007). Vivir en policía: Una contralectura de los orígenes del derecho administrativo colombiano. Bogotá: Universidad Externado de Colombia.

Narváez, J. R. (2005). La persona en el derecho civil: historia de un concepto jurídico. México: Porrúa.

Novarese, D. (2000). Istituzioni e processo di codificazione nel regno delle due Sicilie. Le "leggi penali” del 1819. Milano: Giuffrè.

Ots, J. M. (1974). Sobre la vigencia efectiva de las partidas en América. En Estudios jurídicos 
en homenaje al profesor Santa Cruz Teijeiro. Tomo 2 (pp. 173-182). Valencia: Universidad de Valencia.

Paine, T. (2004). Rights of Man (1791). New York: Barnes \& Noble.

Pérez, R. (2004). Los abogados de América Latina: una introducción histórica. Bogotá: Universidad Externado de Colombia.

Petit, C. (2005). De la historia a la memoria. A propósito de una reciente obra de historia universitaria. Cuadernos del Instituto Antonio de Nebrija de historia de la universidad, 8, 237-279.

Petit, C. (2008). España y el Code Napoléon. En Anuario de Derecho Civil, 61.

Petit, C. (1995). El Código inexistente: Por una historia conceptual de la cultura jurídica en la España del siglo XIX. Historia contemporánea, 12, 49-90.

Rabinovich, R. (2006). Principios generales del derecho latinoamericano. Buenos Aires: Astrea.

Restrepo, J. M. (1942). Historia de la revolución de la República de Colombia en la América Meridional. Tomo I. Bogotá: Biblioteca Popular de Cultura Colombiana.
Rodríguez, M. (1984). El experimento de Cádiz en Centroamérica, 1808-1826. Trad. Marita Martínez del Río de Redo. México: Fondo de Cultura Económica.

Romero, J. L. \& Romero, L. A. (1985). El pensamiento político de la emancipación. Selección, notas y cronología). 1. Barcelona: Biblioteca Ayacucho.

Simon, T. (2009, Julio-Diciembre). ¿Qué es y para qué sirve la legislación? Trad. Andrea Macía. Vniversitas, 119, p. 371-394.

Thury, V. (2003). Raíces y prospectiva del proceso de codificación. En AA.WV. La codificación: raíces y prospectiva. (p. 255-266). Buenos Aires: UCA.

Uribe, D. (1997). Las constituciones de Colombia. Tomo I. Madrid: Cultura Hispánica.

Urrego, M. A. (1998, Marzo). Mitos fundacionales, reforma política y nación en Colombia. Nómadas, 8, 10-18.

Vallejo, J. (1992). Ruda Equidad, ley consumada. Concepción de la potestad normativa (12501350). Madrid: CEC.

Wieaker, F. (1957). Historia del derecho privado de la Edad Moderna. Madrid: Aguilar. 